\title{
APONTAMENTOS CRÍTICOS EM TORNO DO DEBATE SOBRE A CENTRALIDADE/NÃO- CENTRALIDADE DO TRABALHO
}

\author{
HENRIQUE AMORIM ${ }^{1}$
}

Este texto tem como objetivo desenvolver a seguinte afirmação: o debate sobre a centralidade do trabalho e a não centralidade do trabalho fundamenta-se como um debate retórico, pois se articula dentro de uma mesma e antiga problemática humanista que prevê a retomada, por parte da classe trabalhadora, de sua consciência política.

Com base em duas teses centrais não excludentes, essa retomada pode ser caracterizada. A primeira tese se fundamenta na idéia de que a classe trabalhadora, ou ainda, o próprio trabalhador isolado, poderia reconquistar sua consciência de classe no momento em que retomasse o controle dos processos de trabalho. A segunda se caracteriza pela compreensão de que o processo de retomada dessa consciência estaria dissociado da vontade política da classe trabalhadora: a história da lutas de classes seria, então, motivada por forças autônomas como, por exemplo, o desenvolvimento científico e tecnológico. Essas duas teses fundamentaram leituras as mais variadas sobre o trabalho durante o século XX. Leituras que caracterizaram a homogeneidade da classe trabalhadora nos anos 1960 e $1970^{2}$, para demons-

\footnotetext{
${ }^{1}$ Doutorando em Ciências Sociais pelo Instituto de Filosofia e Ciências Humanas (IFCH), na Universidade Estadual de Campinas (UNICAMP).

${ }^{2}$ Ver Georges Friedman, O Trabalho em Migalhas. São Paulo: Perspectiva, 1972 e Georges Friedman, Pierre Naville, Traité de Sociologie du Travail. Paris: Librairie
} 
trar sua capacidade revolucionária, e que são inversamente e equivocadamente reformuladas nas décadas de 1980 e $1990^{3}$ para demonstrar sua heterogeneidade e, assim, a sua incapacidade revolucionária diante da acachapante racionalidade da economia capitalista.

O debate sobre a centralidade/não-centralidade do trabalho nas décadas de 1980 e 1990 fundamenta-se como uma inversão teórica dentro de uma mesma e antiga problemática que reduziu o trabalho a uma atividade naturalmente emancipatória e que nas últimas duas décadas acaba por reduzi-lo a pó.

Mostra-se necessário, assim, apresentar os pressupostos analíticos que informam esse debate como uma possível reedição de temas que, em conjunturas sociais anteriores, foram utilizados como argumentos efetivos de sua base teórica política e que, nas duas últimas décadas, acabaram por se organizar dentro de uma linha teórica que tentou rechaçar a capacidade de organização política da classe trabalhadora no capitalismo, através de uma suposta mudança paradigmática, de um aparente deslocamento de problemática ${ }^{4}$.

Para fundamentarmos esta perspectiva, indicamos que a problemática que salvaguarda os fundamentos do debate sobre a centralidade do trabalho na atualidade pode ser relacionada e remontada a partir das origens da sociologia do trabalho no século XX. Nesse sentido, a retomada da conjuntura referente à difusão do taylorismo e ao surgimento da moderna sociologia do trabalho tornar-se-ia central para a análise dos pressupostos que balizam o assim chamado debate sobre "o mundo do trabalho".

Armand Colin, 1964, vols. I e II.

${ }^{3}$ Ver André Gorz. Adeus ao Proletariado - Para Além do Socialismo. Rio de Janeiro: Forense, 1987 e Métamorphoses du Travail. Quête du Sens: critique de la raison economique. Paris: Galilée, 1988, Claus Offe, Trabalho e sociedade. Rio de Janeiro: Tempo Brasileiro, vol. I, 1989, Robert Kurz, O colapso da modernização (da derrocada do socialismo de caserna à crise da economia mundial. São Paulo: Paz e Terra, 1992, entre outros.

${ }^{4} \mathrm{O}$ paradigma produtivo seria superado dando lugar a novos paradigmas sociais situados, sobretudo, na esfera do mercado (da circulação). 
Relendo esse percurso analítico, poderemos indicar que as teses que informam historicamente os grandes embates entre racionalidades científicas no debate sobre as relações de trabalho no século XX estruturam-se com base nos pressupostos que determinaram, por parte da esquerda marxista, por exemplo, a longa discussão sobre o primado das forças produtivas sobre as relações de produção, ou também, do caráter revolucionário da "nova classe operária" do final dos anos sessenta, reproduzido pelo ideal de classe homogênea presente nas abordagens de autores como André Gorz ${ }^{5}$, Serge Mallet $^{6}$ e Radovan Richta ${ }^{7}$.

Partindo dessa compreensão do problema, analisamos as expressões teóricas fundamentais desse debate para explicitarmos as teses decisivas no seio do debate sobre a crise do trabalho nas sociedades contemporâneas, com a finalidade de indicar o reducionismo analítico de determinadas formulações que precedem em muito (como, por exemplo, Gorz, 1968a e 1968b e Mallet, 1969) os principais encaminhamentos teóricos do debate atual.

Com isso, indicamos que os períodos de crise do capital, marcados por redefinições nas formas da exploração da força de trabalho, acabam por redirecionar as linhas da pesquisa científica em presença e a subordinar a história da luta de classes ao ponto de vista da classe dominante.

Deve-se frisar que estas transformações, no seio da produção, têm, em primeira instância, a intenção de desqualificar a força de trabalho ${ }^{8}$ para

${ }^{5}$ André Gorz, Estratégia Operária e Neocapitalismo. Rio de Janeiro: Zahar, 1968(a) e Socialismo Difícil. Rio de Janeiro: Zahar, 1968(b).

${ }^{6}$ Serge Mallet, La Nouvelle Classe Ouvrière. Paris: Éditions du Seuil, 1969 e Le Pouvoir Ouvrier: Bureaucratie ou Democratie Ouvrière. Paris: Anthropos, 1971.

${ }^{7}$ Radovan Richta, Economia Socialista e Revolução Tecnológica. Rio de Janeiro: Paz e Terra, 1972.

${ }^{8}$ Hoje presenciamos uma tendência de aparente qualificação intelectual de parte da classe trabalhadora, explicitada, sobretudo, pelas formas do trabalho imaterial. Um tipo de trabalhador ligado a uma necessária informatização de sua ocupação profissional elevaria os níveis intelectuais de seu trabalho e de sua consciência crítica. Essa necessária aparência, em última instância, corrobora a lógica de valorização do capital no sentido 
conter a tendência de diminuição da taxa de lucro, conservando a reprodução da estrutura de classes. Contudo, devemos precisar, ainda, que as reestruturações produtivas qualificam-se como forma necessária e determinante da reprodução das classes trabalhadoras e de sua dominação.

Dessa maneira, devemos colocar em questão a forma pela qual este debate foi construído. Calcado na perspectiva de que a classe trabalhadora seria profundamente heterogênea, este debate pode ser observado, sobretudo, quando a tese sobre a inexorabilidade do desenvolvimento das forças produtivas é retomada (seja em sua positividade ou negatividade). Em decorrência, as análises sobre o potencial revolucionário das classes trabalhadoras ${ }^{9}$, de suas estratégias de luta política e de sua resistência política, acabam por restringir-se ao seu núcleo operário, não atualizando os conceitos de produção, trabalho e dos antagonismos sociais em presença.

A determinação predominante acaba equivocadamente sendo marcada pelo primado das forças produtivas sobre as relações de produção; primado este que se fundamenta de maneira autônoma e positiva qualificando a ciência e a técnica como forças de produção insubordináveis dentro das sociedades de capitalismo avançado.

Nesse sentido, não só as relações de produção estariam submetidas à lógica desse desenvolvimento, mas a construção da história humana se-

de salvaguardar e ampliar as formas de sua reprodução. Ver sobre esse tema Maurizio Lazzarato, "O conceito de trabalho imaterial: a grande empresa". In: Futur Antérieur, $\mathrm{n}^{\circ} 10,1992$, pp. 1-9, tradução de Angela Maria Tude de Souza (mimeo), Antonio Negri, Jean M. Vincent, "Paradoxes autour du travail". In: Futur Antérieur, 1992, n. ${ }^{\circ}$ 10, pp. 5-8, Andre Tosel, "Centralidade e não-centralidade do trabalho ou a paixão dos homens supérfluos”. In: Jaques Bidet e Jaques Texier. La Crise du Travail. Paris: PUF, 1992, pp. 1-12, tradução de Angela Maria Tude de Souza (mimeo).

Jean M. Vincent "Os automatismos sociais e o 'general intelect”. In: Futur Antérieur, 1993, n 16, pp.1-15, tradução de Angela Maria Tude de Souza (mimeo), entre outros.

${ }^{9}$ Selecionamos aqui algumas análises que expõem sinteticamente as teses centrais da sociologia do trabalho: as análises da sociologia humanista, de Georges Friedmann, $O$ Trabalho em Migalhas. São Paulo: Perspectiva, 1972, da sociologia da alienação, de André Gorz, (op.cit., 1968a e 1968b); da sociologia tecnicista de Serge Mallet, (op.cit., 1969) e do debate sociológico atual que afirmam a não centralidade do trabalho, como André Gorz, (op.cit., 1987). 
ria reduzida ao movimento de sua base material e econômica, as forças produtivas corresponderiam, nesse esquema, a um conjunto de coisas enumeráveis ${ }^{10}$.

Formam-se, assim, no século XX, duas perspectivas dominantes na análise das mutações dos processos de trabalho: a primeira vincula estreitamente estas à retomada de consciência de classe, ao desenvolvimento da técnica e da ciência; e a segunda, ao denunciar a negatividade do desenvolvimento das forças produtivas, afirma não apenas a necessidade de humanização do trabalho, mas principalmente a impossibilidade de superação das estruturas capitalistas limitadas à esfera do trabalho e da classe operária. Este é o núcleo teórico da perspectiva que denominamos reducionista.

Segundo o nosso ponto de vista, devemos, contrariamente, questionar a natureza da produção e do trabalho, comparando as transformações introduzidas pelo taylorismo às da automação, na tentativa de requalificar os conceitos e as transformações dos processos de trabalho como variações dentro de uma mesma natureza de classe, questionando a existência de uma ruptura estrutural (como afirmam os teóricos sobre a não centralidade do trabalho) ou de uma continuidade nessas transformações. Quais seriam, assim, seus elementos de ruptura? Seriam formas de evolução das relações de produção ou novamente uma reorganização da subalternidade da classe trabalhadora?

Em linhas gerais, afirmamos que a raiz do debate sobre a nãocentralidade do trabalho não é atual. Essa questão remonta às conjunturas precedentes, como tentamos preliminarmente indicar. A partir dessa perspectiva podemos encontrar alguns dos elementos centrais para fundamentar a crítica às teses sobre a não-centralidade do trabalho.

${ }^{10}$ Para uma melhor compreensão da discussão sobre a relação entre forças produtivas e relações de produção, ver, por exemplo, A. D. Magaline, Luta de classes e desvalorização do capital. Lisboa: Moraes, 1977, A. Azouvi, "Progrès technique et rapports de production: de la théorie à l'enquête". In: Critiques de l'économie politique. Nouvelle Série, no 10, 1980, pp. 03-28, Etiene Balibar, "Sobre os conceitos funda,entais do materialismo histórico". In: Louis Althusser, Etiene Balibar, Roger Establet, Ler o Capital. Rio de Janeiro: Zahar, volume II, 1980, Robert Linhart, Lenin, os camponeses, Taylor. Rio de Janeiro: Marco Zero, 1983. 
A determinação da não centralidade do trabalho é concebida a partir das inevitáveis forças mobilizadas pela ciência e pela técnica. André Gorz ${ }^{11}$ (1987, 1988 e 1991), por exemplo, vislumbra uma sociedade dual, na qual a parte heterônoma da produção social seria involuntariamente preservada, já que as relações de produção e a exploração capitalista manifestar-se-iam como relações sociais insuperáveis, haja visto, a necessidade dos produtos e serviços por ela fornecidos.

Nesse sentido, Gorz ${ }^{12}$ buscou relativizar o trabalho e as suas mais vorazes conceituações, já que por quase todo o século XX a produção imediata, como categoria analítica, permitiu explicitar a luta de classes dentro e fora da produção. Nos termos em que Gorz considera o aprofundamento da divisão do trabalho, algumas hipóteses durkheimianas são retomadas, sobretudo quanto à heterogeneidade da classe trabalhadora. Hipóteses essas que fundamentaram toda uma linha de análise marxista durante o século XX, que é requalificada à luz das transformações nos processos de trabalho, leiase modernização das relações de trabalho, microeletrônica, diminuição dos postos de trabalho e aumento da diversidade das novas ocupações produtivas, garantindo uma necessária dominação ideológica e a sua sistematização no campo científico.

Para Gorz, a heterogeneidade da classe trabalhadora, por um lado, mostrar-se-ia como um fator a ser considerado dentro do horizonte de unificação política e sindical mas, por outro, não pode encerrar a discussão sobre a fragilidade ou não da organização do movimento operário em uma dada conjuntura em que se presencia uma forte ofensiva das classes dirigentes, como a atual.

${ }^{11}$ Ver André Gorz, Adeus ao proletariado, op.cit., 1987, Métamorfhoses du travail. Quête du sens: critique de la raison economique, op.cit., 1988 e Capitalisme, Socialisme, Écologie. Paris: Galilée, 1991.

${ }^{12}$ Do nosso ponto de vista, a obra de Gorz dos anos 1980 e 90 pode sintetizar o que aqui apresentamos como uma perspectiva que tenta romper com os pressupostos marxistas, na medida em que desvincula o trabalho como forma central de organização da vida na sociedade capitalista. Do mesmo autor ver também Les Chemins du Paradis: l'agonie du capital. Paris: Galilée: 1983; Capitalisme, Socialisme, Écologie. Paris: Galilée, 1991 e "A Nova Agenda". In: Robin Blackburn (org.), Depois da queda: o fracasso do comunismo e o futuro do socialismo. São Paulo: Paz e Terra, 1993. 
Essa heterogeneidade parece caracterizar, nos termos em que Gorz a apresenta $^{13}$, a inevitabilidade do declínio político e reivindicativo da classe trabalhadora, haja visto, a impossibilidade de superação da produção heterônoma, com base na (des)alienação dos trabalhadores.

Dessa forma, o convívio com a "anomia" social, circunscrita por Gorz ao terreno da heteronomia, caracterizaria a necessidade de criação de uma sociabilidade que transcendesse os domínios do Estado burguês. Em conseqüência, o adensamento de uma solidariedade social, a partir de regulamentações sociais desenvolvidas na esfera do mercado e da divisão social do trabalho, tornar-se-ia, dentro dessa perspectiva, imprescindível.

Assim, a necessidade de afirmação de um consenso social (de um adensamento moral dos laços sociais), face ao aprofundamento do individualismo egoísta e de uma insuperável alienação do trabalho, poderia responder ao caráter anômico engendrado ou até mesmo exacerbado pelo capitalismo industrial e financeiro. Nesse sentido, a formação de um "tecido social" limitaria a intervenção do Estado, mas não deixaria a cargo do mercado a sua própria regulação social.

Decorre daí que a liberação do trabalhador com relação ao tempo de trabalho the garantiria desempenhar uma "ação" política na esfera autônoma da vida social. Essa poïésis, tão aclamada por Gorz, e atada à suposta esfera da autonomia individual ${ }^{14}$, demonstra não só o caráter reducionista de sua análise, mas também a alinha, sobremaneira, às proposições da Teoria da Ação ${ }^{15}$.

${ }^{13}$ Mas não só ele, ver também Claus Offe, Trabalho e sociedade. Rio de Janeiro: Tempo Brasileiro, vol. 1, 1989), Jürgen Habermas, Teoria de la acción comunicativa. Madrid: Taurus, 1987 e "A revolução e a necessidade de revisão da esquerda - o que significa socialismo?”. In: Blackburn, op.cit., 1993, entre outros.

${ }^{1}$ A alternativa apresentada por Gorz caracteriza-se como uma saída ética, já que a esfera da heteronomia não pode ser suprimida (cf.: Vincent e Negri, "Paradoxes autour du travail", op.cit.).

${ }^{14}$ A alternativa apresentada por Gorz caracteriza-se como uma saída ética, já que a esfera da heteronomia não pode ser suprimida (cf.: Vincent e Negri, "Paradoxes autour du travail", op.cit., 1992).

${ }^{15}$ Sobre a Teoria da Ação, ver Habermas, Teoria de la acción comunicativa,op.cit., 1987 
Nesse sentido, a substituição idealizada da perspectiva dos macrosujeitos (classes sociais, Estado, partidos, etc.) pela ação individual de agentes consumidores, que, segundo Gorz, teriam consciência do que e como consomem $^{16}$, faz aflorar os termos reducionistas com que trata a problemática das classes sociais na contemporaneidade.

O debate atual sobre a não centralidade do trabalho exprime, enfim, o amadurecimento consciente dos embates entre racionalidades científicas explicitados na virada dos 60 e 70, no sentido em que produz uma inflexão, não de uma concepção histórica sobre as transformações no e do trabalho, mas sim, de um sujeito histórico ideal condicionado por um suposto núcleo social homogêneo definido por sua condição autônoma frente aos processos de valorização e acumulação.

Portanto, as muitas problematizações acerca do debate sobre a não centralidade do trabalho na atualidade, representadas aqui pela (re)leitura de parte da obra de André Gorz, confirmam-se dentro de uma perspectiva reducionista, reproduzindo, assim, sob uma nova roupagem e dentro de uma conjuntura distinta, algumas das formulações suscitadas pela aparição de uma "nova" classe operária no interregno das duas grandes guerras mundiais.

e, para a sua crítica, ver André Tosel, "Quelle pensée de l'action aujourd'hui?". In: Actuel Marx, Les théories de l'action aujourd'hui, no 13, 1993.

${ }^{16}$ André Gorz, Métamorphoses du Travail. Quête du Sens: critique de la raison economique, op.cit., p. 36.

54 APONTAMENTOS CRÍTICOS EM TORNO DO DEBATE SOBRE A CENTRALIDADE/NÃO-... 